\title{
OPEN High surface area micro-mesoporous graphene for electrochemical applications
}

\author{
Piotr Kamedulski ${ }^{1,2}$, Malgorzata Skorupska ${ }^{1}$, Pawel Binkowski ${ }^{1}$, Weronika Arendarska ${ }^{1}$, \\ Anna Ilnicka ${ }^{1} \&$ Jerzy P. Lukaszewicz ${ }^{1,2 \bowtie}$
}

The manuscript presents results on the influence of external pressure on graphene exfoliation and subsequent 3D structuring by means of liquid-phase exfoliation. In contrast to known and applied exfoliation methods, the current study exploits the enhancement of splitting forces caused by the application of high pressure. The manufacturing pathway allowed to increase the surface area from $750 \mathrm{~m}^{2} / \mathrm{g}$ (nanoplatelets) to ca. $1100 \mathrm{~m}^{2} / \mathrm{g}$ (after 3D structuring). Electrochemical studies revealed that the 3D graphene materials were active in the oxygen reduction reaction (ORR). The outstanding ORR activity of 3D structured graphene materials should not be ascribed to heteroatom catalytic centers since such heteroatoms were successively removed upon increasing the carbonization temperature. XPS data showed that the presence of transition metals and nitrogen (usually regarded as catalytic centers) in G-materials was marginal. The results highlight the importance of structural factors of electrodes in the case of graphene-based materials for $\mathrm{Zn}$-air batteries and ORR.

Graphene still attracts researchers' attention due to some outstanding features, such as high (almost "metallic") electric conductivity, heteroatom insertion ability, and high chemical stability. The feature might predestine graphene for an ideal electrode material in electrochemical devices like batteries and supercapacitors. However, two important features of common electrode materials cannot be ascribed to pristine, i.e. strictly monolayer graphene: low manufacturing cost as well as a well-developed surface area and pore structure. Although a surface area of $2640 \mathrm{~m}^{2} / \mathrm{g}$ should be theoretically expected from graphene, real graphene samples, mainly nanoplatelets, exhibit a much less developed surface area of $10-750 \mathrm{~m}^{2} / \mathrm{g}^{1,2}$. This fact, along with a relatively high price of typical 2D graphene ${ }^{3}$, turned researchers' attention to other sources of graphene, i.e. graphite and its exfoliation to less agglomerated structures. Several exfoliation methods were reported, such as liquid-phase, electrochemical, mechanical and microwave ${ }^{4-12}$. Liquid-phase exfoliation is regarded as a scalable method yielding graphene flakes of high quality and purity and low agglomeration ${ }^{13}$. The quality of such exfoliated graphene sheets may be as high as for graphene sheets obtained by chemical vapour deposition or SiC-based synthesis. However, liquidphase exfoliation does not solve the problem of the lack of a durable pore structure resulting from the exfoliation process. The interflake spaces, even if created, collapse after the removal of the liquid phase. To avoid this effect, which practically excludes exfoliated graphene from electrode manufacturing, some additional measures must be undertaken. Such procedures should fix the split flakes at a certain distance from each other. Thus, in our previous studies, the liquid phase splitting was supplemented by the 3D structuring of exfoliated graphene flakes ${ }^{14-16}$. 3D structuring employs a nanopowder, of which particles (so-called hard template) penetrate the newly formed spaces between the exfoliated graphene flakes, providing a permanent separation of them and avoiding a secondary stacking due to $\pi-\pi$ attracting forces. Polyfurfuryl alcohol was used as "carbon glue" for a durable fixation of the obtained 3D-structured graphene flakes. Although the manufacturing scenario was practised recently, the answer to an important question is still missing: which factors may support the process of spontaneous graphene flake splitting in the liquid phase. Originally, the process relies on the appropriate surface tension of the liquid and the wettability of the graphene surface. Too high surface tension and too low wettability prevent the penetration of the dispersing liquid in-between the stack graphene flakes and hinder their subsequent separation. Thus, a hypothesis was raised that external high pressure set on the dispersing liquid should increase the effectiveness of the whole exfoliation process. The current paper addresses this pressure-exfoliation issue and is intending, as a pioneering study, to prove the positive influence of forced liquid exfoliation of graphene nanoplates to less agglomerated graphene structures, which can be structured to 3D electrode materials.

${ }^{1}$ Faculty of Chemistry, Nicolaus Copernicus University, Gagarina 7, 87-100 Torun, Poland. ${ }^{2}$ Centre for Modern Interdisciplinary Technologies, Nicolaus Copernicus University, Wilenska 4, 87-100 Torun, Poland. ${ }^{\bowtie}$ email: jerzy_ lukaszewicz@o2.pl 


\section{Materials and methods}

Sample preparation. Mesoporous graphene was formulated similar to our previously published protocols ${ }^{17}$. In summary, $2 \mathrm{~g}$ of pristine graphene nanoplatelets (Sigma-Aldrich 900407 , surface area $750 \mathrm{~m}^{2} / \mathrm{g}$ ) was added to $4 \mathrm{~g}$ of $\mathrm{CaCO}_{3}$ (SkySpring Nanomaterials, INC., average particle size of $15-40 \mathrm{~nm}$ ) and mixed mechanically. Then, $20 \mathrm{ml}$ of 1-methyl-2-pyrrolidinone, NMP (Sigma-Aldrich, 443778) with $0.1 \mathrm{ml}$ of cationic surfactant CTAC was added and mixed well. Next, the flask was placed for $1 \mathrm{~h}$ in an ultrasonic bath (room temperature) and then, $15 \mathrm{ml}$ of furfuryl alcohol (POCh) was added, mixed with 3 drops of concentrated phosphoric acid aqueous solutions (75\%) in an ARE-250 planetary mixer. Next, everything was poured into a Teflon container and finally placed in a miniclave drive pressure reactor (Büchiglasuster, Switzerland). The temperature $\left(-0.55^{\circ} \mathrm{C}\right)$ in the reactor was kept constant for $2 \mathrm{~h}$ at a pressure of $12 \mathrm{bar}$. After $2 \mathrm{~h}$, the temperature was increased sharply to $25^{\circ} \mathrm{C}$. Then, it was dried in an electric furnace at $50{ }^{\circ} \mathrm{C}$ for $2 \mathrm{~h}$. Next, the material was divided into four samples for carbonization at temperatures in the range of $700-900^{\circ} \mathrm{C}$. The mass was heated under the flow of nitrogen at a rate of $10^{\circ} \mathrm{C} / \mathrm{min}$ in a tube furnace (Thermolyne F21100). After this process, the prepared samples remained in a tube furnace under the flow of nitrogen in order to reach room temperature. After carbonization, the samples were treated as in our previous works ${ }^{17,18}$ with concentrated $(34-37 \%) \mathrm{HCl}$ for $20 \mathrm{~min}$ ( $1 \mathrm{~g}$ of carbon was used per $12 \mathrm{ml}$ of $\mathrm{HCl}$ ) and then washed with distilled water using a Büchner funnel, until the $\mathrm{pH}$ of the solution reached 6-7. The action of $\mathrm{HCl}$ opened pores in the carbon matrix by etching the template. Then, it was dried in an electric furnace at $100{ }^{\circ} \mathrm{C}$ for $24 \mathrm{~h}^{17,18}$. The term $3 \mathrm{D}$ graphene is when graphene flakes get stack randomly in a $3 \mathrm{D}$ volume ${ }^{19-24}$. Thus, we receive a $3 \mathrm{D}$ bulky structure (graphene flakes are building stones) resembling a sponge. "3D Graphene" is only a mental shortcut. The "3D structured graphene flakes" is a better description, however too long to be commonly permanently, and therefore we consequently use shorter forms in the text. The three-dimensional graphene samples obtained in the proposed method were denoted as G-T, where T means the carbonization temperature of $700^{\circ} \mathrm{C}(\mathrm{G}-700), 800{ }^{\circ} \mathrm{C}(\mathrm{G}-800)$ or $900{ }^{\circ} \mathrm{C}(\mathrm{G}-900)$. The precursor of $3 \mathrm{D}$ materials is called GF-750.

Methods of analysis. The morphology of the obtained high surface mesoporous graphene was analyzed by scanning electron microscopy with STEM mode (SEM, 1430 VP, LEO Electron Microscopy Ltd., Oberkochen, Germany) and high-resolution transmission electron microscopy (HRTEM, FEI Europeproduction, model Tecnai F20 X-Twin, Brno, Czech Republic). The graphene samples obtained prior to the HRTEM microscopic analysis were dispersed in ethanol and treated with an Inter Sonic IS-1K bath for $15 \mathrm{~min}$ and deposited on holey carbon-coated copper grids. The volumetric elemental composition $(\mathrm{C}, \mathrm{N}, \mathrm{H})$ of the materials was analyzed by means of a combustion elementalanalyzer (Vario MACRO CHN, Elementar Analysensysteme GmbH, Langenselbold, Germany). The structural properties and nitrogen sorption isotherms of obtained graphene materials were determined by nitrogen physisorption experiments at $-196{ }^{\circ} \mathrm{C}$ using an ASAP 2020 Plus instrument (Micromeritics, USA). The surface area was calculated by the Brunauer-Emmett-Teller (BET) model. The pore size distributions were determined from the nonlocalized density functional theory (NLDFT) method in the SAIEUS program. The hysteresis loop area in adsorption units $\left(\mathrm{cm}^{3} \mathrm{~g}^{-1}\right)$ was obtained as a result of numerical integration as the difference of the surface area under the desorption and adsorption branches. Raman spectra were obtained by a micro-Raman spectrometer (laser wavelength $532 \mathrm{~nm}$, Senterra, Bruker Optik, Billerica, MA, USA). The laser was tightly focused on the sample surface through a $50 \times$ microscope objective. To prevent any damage to the sample, excitation power was fixed at $2 \mathrm{~mW}$. The resolution was $4 \mathrm{~cm}^{-1}$, CCD temperature $223 \mathrm{~K}$, laser spot diameter $2.0 \mu \mathrm{m}$, and total integration time $100 \mathrm{~s}(50 \times 2 \mathrm{~s})$ were used. X-ray photoelectron spectroscopy (XPS, PHI5000 VersaProbe II Scanning XPS Microprobe, Chigasaki, Japan) measurements were performed using a monochromatic $\mathrm{Al} \mathrm{Ka} \mathrm{X-ray} \mathrm{source.} \mathrm{Survey} \mathrm{spectra} \mathrm{were} \mathrm{recorded} \mathrm{for} \mathrm{all} \mathrm{samples} \mathrm{in} \mathrm{the} \mathrm{energy} \mathrm{range}$ of $0-1300 \mathrm{eV}$ with a $0.5 \mathrm{eV}$ step, high-resolution spectra were recorded with a $0.1 \mathrm{eV}$ step. The electrochemical studies of the oxygen reduction reaction (ORR) and $\mathrm{Zn}$-air batteries measurements were carried out with a potentiostat (Autolab, PGSTAT128N, Netherland) and were performed according to methods published in our other article ${ }^{14,17}$.

Electrochemical measurements ORR. The electrochemical studies of the oxygen reduction reaction (ORR) were carried out with a potentiostat (Autolab, PGSTAT128N, Netherland). The tests were performed in a three-electrode system, in which $\mathrm{Ag} / \mathrm{AgCl}$ was used as the reference electrode, the platinum plate was the counter electrode, and the glassy carbon (GC, diameter $5 \mathrm{~mm}$ ) with the applied catalyst as the working electrode. The performed potential measurements were converted in relation to the RHE hydrogen electrode (Reversible Hydrogen Electrode). An ink for electrochemical measurements was prepared by dispersing $2.5 \mathrm{mg}$ of carbon catalyst together with distilled water, ethanol and aqueous Nafion ( 0.5 wt.\% aqueous solution) for $60 \mathrm{~min}$. An appropriate amount of the catalyst was applied to the glassy carbon, and then the solvents were allowed to dry for a few minutes. The results of the catalytic activity were carried out in saturated $\mathrm{O}_{2}$ and $\mathrm{N}_{2}$ electrolyte of $0.1 \mathrm{M}$ $\mathrm{KOH}$. The catalytic activity of all measured carbon materials was compared to a platinum-based commercial carbon material (20 wt.\% Of Pt, Sigma Aldrich) as reference material. Cyclic voltammetry (CV) results were recorded at a $10 \mathrm{mV} \mathrm{s}^{-1}$ scan rate and in the potential range from 0 to $0.8 \mathrm{~V}$, while linear sweep voltammetry (LSV) data was recorded at a $5 \mathrm{mV} \mathrm{s}^{-1}$ scan rate and a rotating disk electrode (RDE) speed in the range from 800 to $2800 \mathrm{rpm}$. The number of electrons (n) taking part in the oxygen reduction reaction was calculated on the basis of the LSV plot using the Koutecky-Levich (K-L) formulas presented below:

$$
\mathrm{J}^{-1}=\mathrm{J}_{\mathrm{L}}^{-1}+\mathrm{J}_{\mathrm{K}}^{-1}=\left(\mathrm{B} \omega^{1 / 2}\right)^{-1}+\mathrm{J}_{\mathrm{K}}^{-1}
$$




\begin{tabular}{|c|c|c|c|c|c|c|c|c|c|c|}
\hline \multirow[b]{2}{*}{ Carbon sample } & \multicolumn{4}{|c|}{$\begin{array}{l}\text { Elemental content (wt.\%) (combustion } \\
\text { method) }\end{array}$} & \multirow[b]{2}{*}{$\mathrm{S}_{\mathrm{BET}}\left(\mathrm{m}^{2} \mathrm{~g}^{-1}\right)$} & \multirow[b]{2}{*}{$\mathrm{S}_{\text {loop hysteresis }}\left(\mathrm{cm}^{3} \mathrm{~g}^{-1}\right)$} & \multirow[b]{2}{*}{$V_{t}\left(\mathrm{~cm}^{3} \mathrm{~g}^{-1}\right)$} & \multirow[b]{2}{*}{$V_{m i}\left(\mathrm{~cm}^{3} \mathrm{~g}^{-1}\right)$} & \multirow[b]{2}{*}{$V_{m e}\left(\mathrm{~cm}^{3} \mathrm{~g}^{-1}\right)$} & \multirow[b]{2}{*}{$\mathbf{V}_{\mathrm{me}} / \mathbf{V}_{\mathrm{t}}(\%)$} \\
\hline & C & $\mathbf{H}$ & $\mathbf{N}$ & Residue & & & & & & \\
\hline GF-750 & 87.32 & 0.90 & 0.72 & 11.06 & 750 & 9.26 & 0.999 & 0.127 & 0.873 & 87 \\
\hline G-700 & 88.81 & 0.88 & 0.46 & 9.85 & 879 & 10.36 & 1.143 & 0.099 & 1.044 & 91 \\
\hline G-800 & 89.17 & 0.87 & 0.53 & 9.43 & 805 & 10.97 & 1.090 & 0.104 & 0.987 & 91 \\
\hline G-900 & 93.16 & 0.71 & 0.52 & 5.61 & 1034 & 17.05 & 1.452 & 0.141 & 1.311 & 90 \\
\hline
\end{tabular}

Table 1. Basic properties of graphene nanoplatelets and electrode materials derived therefrom.

\begin{tabular}{|c|c|c|c|c|c|c|c|c|c|c|c|c|}
\hline \multirow{3}{*}{\begin{tabular}{|l} 
Element \\
Binding energy $(\mathrm{eV})$ \\
Carbon sample \\
\end{tabular}} & \multicolumn{8}{|l|}{ C } & \multicolumn{2}{|l|}{0} & \multirow{2}{*}{\multicolumn{2}{|c|}{\begin{tabular}{|l|}
$\mathbf{N}$ \\
400.5
\end{tabular}}} \\
\hline & 284.6 & 285.0 & 286.3 & 287.7 & 288.6 & 289.6 & 292.1 & & 532.0 & 533.3 & & \\
\hline & \multicolumn{7}{|c|}{ Content (at.\%) } & $\%$ of total & \multicolumn{2}{|c|}{ Content (at.\%) } & $\%$ of total & Content (at.\%) \\
\hline GF-750 & 32.6 & 33.4 & 9.7 & 4.4 & 3.8 & 6.8 & 2.6 & 93.3 & 2.0 & 4.8 & 6.8 & 0.0 \\
\hline G-700 & 44.3 & 28.2 & 7.5 & 3.5 & 1.4 & 8.0 & 3.0 & 95.9 & 1.3 & 2.6 & 3.9 & 0.3 \\
\hline G-800 & 45.8 & 25.9 & 7.8 & 3.7 & 1.8 & 8.3 & 3.1 & 96.4 & 1.4 & 2.2 & 3.6 & 0.1 \\
\hline G-900 & 45.2 & 26.1 & 8.4 & 3.7 & 2.1 & 8.1 & 3.1 & 96.7 & 0.7 & 2.6 & 3.3 & 0.0 \\
\hline
\end{tabular}

Table 2. XPS elemental composition of graphene and electrode materials derived therefrom.

$$
\mathrm{B}=0.62 \mathrm{nFC}_{0}\left(\mathrm{D}_{0}\right)^{-2 / 3} v^{-1 / 6}
$$

The individual parameters of the formula can be defined as J measured current density, $\mathrm{J}_{\mathrm{L}}$ is assigned to the limiting current density, and $\mathrm{J}_{\mathrm{K}}$ is defined as the kinetic current density; $\omega$ is the angular velocity of the electrode. The value of $\mathrm{n}$, as mentioned above, is the number of electrons involved in the charge transfer in the oxygen reduction reaction; $\mathrm{F}$ is defined as a Faraday constant of $96,485 \mathrm{C} \mathrm{mol}^{-1} ; \mathrm{C}_{0}$ is the total oxygen concentration in $0.1 \mathrm{M} \mathrm{KOH}$ being $1.2^{\star} 10^{-6} \mathrm{~mol} \mathrm{~L}^{-1} ; \mathrm{D}_{0}$ is the oxygen diffusion coefficient in $0.1 \mathrm{M} \mathrm{KOH}\left(1.9^{*} 10^{-5} \mathrm{~cm}^{2} \mathrm{~s}^{-1}\right) ; v$ is defined as the kinetic viscosity of the electrolyte used $\left(0.01 \mathrm{~cm}^{2} \mathrm{~s}^{-1}\right.$ for $\left.0.1 \mathrm{M} \mathrm{KOH}\right)$. By determining the slope of the K-L plot, it is possible to estimate the number of electrons transferred in the oxygen reduction reaction.

Zn-air battery measurements. The Zn-air battery was prepared to characterize the applicability of the obtained materials. The obtained carbon catalyst played the role of a cathode, and the anode was a zinc plate. To assemble the $\mathrm{Zn}$-air battery, you need a microporous membrane (polypropylene membrane, Celgard 5550) and carbon paper with the catalyst applied, as a separator and current collector, respectively. The ink was prepared by dispersing $10 \mathrm{mg}$ of catalyst with $0.9 \mathrm{ml}$ of a mixture of isopropanol and Nafion solutions (5 wt.\%, Sigma Aldrich) for $1 \mathrm{~h}$. An appropriate amount of the catalyst was applied to carbon paper (packing $1 \mathrm{mg} / \mathrm{cm}^{2}$ ) and then dried at $80{ }^{\circ} \mathrm{C}$ for $30 \mathrm{~min}$. The battery electrolyte was a mixture of $6 \mathrm{M} \mathrm{KOH}$ and $0.2 \mathrm{M} \mathrm{ZnCl}_{2}$ solutions. All results of galvanostatic charge/discharge (600 charge/discharge cycles $-5 / 5 \mathrm{~min}$ ) were carried out on the Autolab potentiostat (PGSTAT302N, the Netherlands). The reference material was an assembled battery with a platinum-based carbon catalyst (20\% Pt, Sigma-Aldrich) as the air electrode.

\section{Results and discussion}

Elemental composition and pore structure. Table 1 presents information on the elemental composition of all investigated materials. The combustion analysis delivers data on the overall elemental content without the split to the surface and bulk composition. The weight share ascribed to the key component, i.e. C, increased upon the rise of carbonization temperature in the range of $700-900^{\circ} \mathrm{C}$. Moreover, the $\mathrm{C}$ content was higher than for the precursor GF-750. The difference to $100 \%$, called a residue, decreases in the same order, which means that it was attributed to a removable element as oxygen. GF-750 was a chemically pure material, which contained only minor amounts of durable impurities. Table 2, containing XPS data, confirmed that assumption. Thus, the C-to-O (residue) ratio reached 16.1 for G-900 in contrast to 7.9 for GF-750 (precursor).

In general, G-materials are more "pure" regarding the content of elemental carbon than the precursor GR-750. The effect is understandable since all G-materials were subjected to intensive thermal elaboration, which obviously led to the elimination of heteroatoms (mainly oxygen) due to the thermal destruction of oxygen species bonded to graphene planes. Figure 1 demonstrates the pore size distribution obtained from the nonlocalized density functional theory (NLDFT) method in the SAIEUS program (Carbon-N2, NLDFT, Standard Slit model). The results confirm the presence of mesopores in the structure of the obtained materials. It is a micro-mesoporous material with a predominant amount of micropores. The pore size distribution shapes indicate that the obtained materials have a similar porous structure. On the other hand, in Fig. 2, the shapes of the hysteresis loops indicate the low presence of mesopores ${ }^{25}$. The hysteresis loops area confirms that the number of mesopores slightly increases with increasing temperature carbonization of the sample. According to the IUPAC classification, all nitrogen adsorption-desorption isotherms for the obtained materials are type II. 

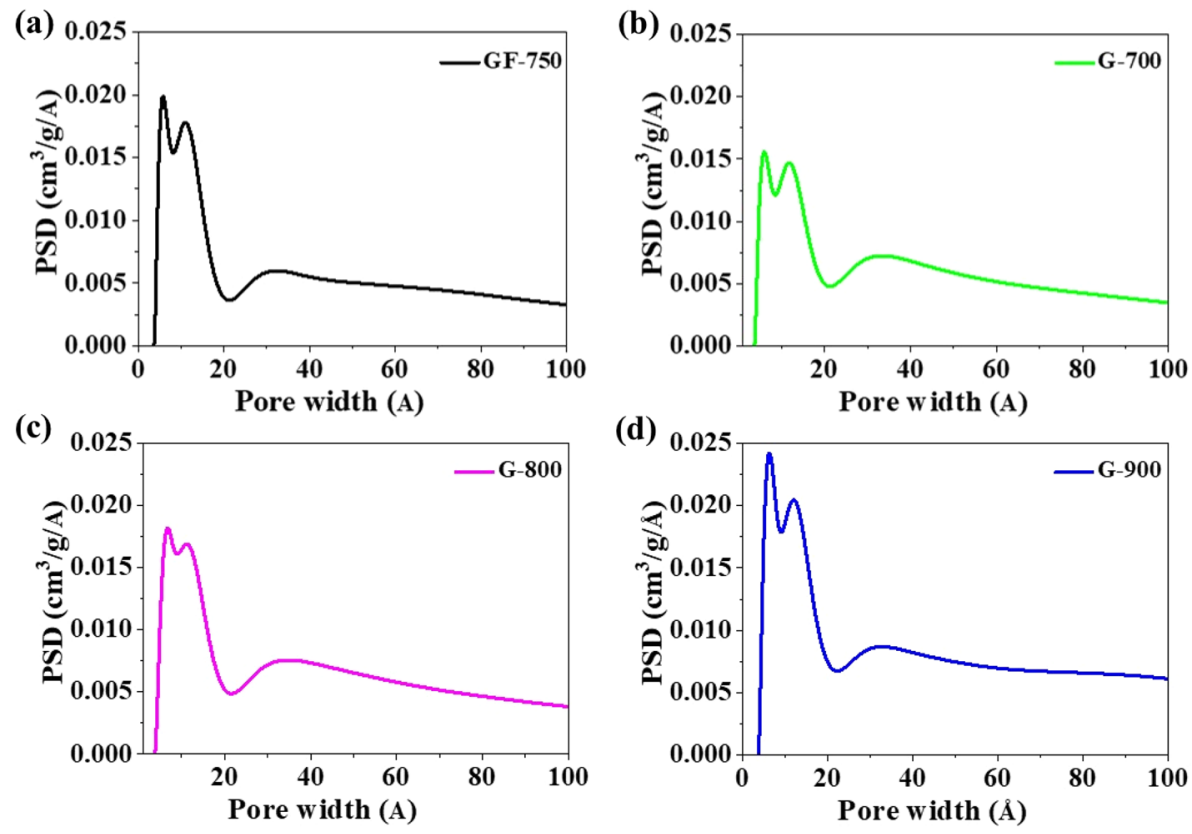

Figure 1. Pore size distribution obtained from adsorption branches of $\mathrm{N}_{2}$ used nonlocalized density functional theory (NLDFT) method of samples (a) GF-750, (b) G-700, (c) G-800 and (d) G-900.
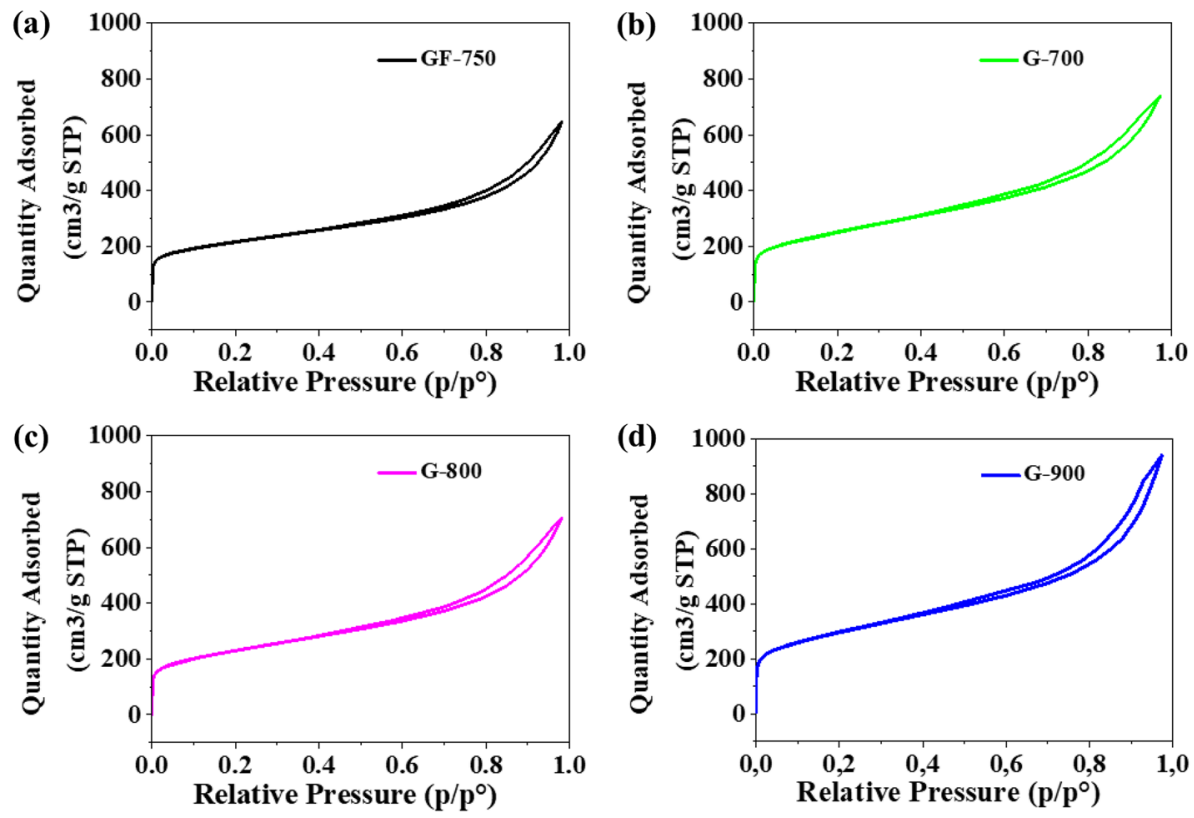

Figure 2. Nitrogen adsorption-desorption isotherms of samples (a) GF-750, (b) G-700, (c) G-800 and (d) G-900.

Table 1 illustrates the surface area improvement in the case of all G-samples in comparison to the precursor, i.e. nanoplatelets. The increase is particularly spectacular (ca. 45\%) for G-900, the material heat-treated at the highest temperature. In parallel, one observed a change of the pore structure, i.e. the total pore volume raised from 0.999 (GF-750) to $1.452 \mathrm{~cm}^{3} / \mathrm{g}$ (G-900). The contribution of the mesopore volume $\mathrm{V}_{\text {me }}$ to the total pore volume $V_{t}$ also increased from 87 to $91 \%$ for all G-samples. All structural improvements, i.e. surface area, total pore volume and the volume share ascribed to mesopores, are particularly expected assuming that the G-materials are expected to be effective electrodes for ORR. A well-developed surface area positively influences the numbers of catalytic centres, while a well-developed and adequately tailored pore structure positively influences molecular transport to and off the electrode surface (reduction of electrode polarization). In summary, the applied manufacturing protocol led to positive structural changes compared to pristine GF-750 graphene nanoplatelets. 


\begin{tabular}{|l|l|l|l|l|l|l|l|l|}
\hline Sample & $\mathbf{I}_{\mathbf{D}}$ & $\mathbf{c m}^{-1}$ & $\mathbf{I}_{\mathbf{G}}$ & $\mathbf{c m}^{-1}$ & $\mathbf{I}_{2 \mathbf{D}}$ & $\mathbf{c m}^{-1}$ & $\mathbf{I}_{\mathbf{D}} / \mathbf{I}_{\mathbf{G}}$ & $\mathbf{I}_{\mathbf{2 D}} / \mathbf{I}_{\mathbf{G}}$ \\
\hline GF-750 & 1.00 & 1344.5 & 0.97 & 1578.0 & 0.44 & 2679.0 & 1.03 & 0.45 \\
\hline G-700 & 0.99 & 1338.5 & 1.00 & 1571.0 & 0.37 & 2679.5 & 0.99 & 0.37 \\
\hline G-800 & 0.99 & 1336.5 & 1.00 & 1568.5 & 0.34 & 2680.0 & 0.99 & 0.34 \\
\hline G-900 & 1.00 & 1337.5 & 0.92 & 1573.0 & 0.34 & 2681.5 & 1.09 & 0.37 \\
\hline
\end{tabular}

Table 3. $\mathrm{D}, \mathrm{G}$ and $2 \mathrm{D}$ band data of Raman spectra.

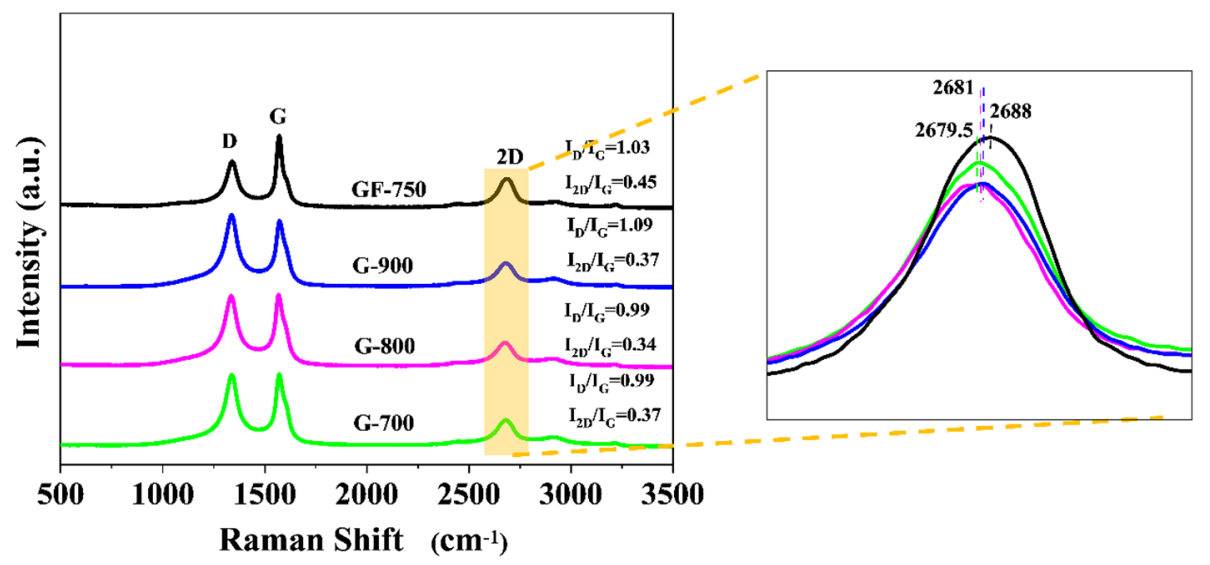

Figure 3. Raman spectra of graphene-based electrode materials.

The XPS data (Table 2) prove that the surface of the investigated G-materials is composed of carbon atoms (atomic content from 93.3 to $96.7 \%$ ) and heteroatoms as $\mathrm{O}$ atoms rarely occur (atomic content from 3.3 to $6.8 \%$ ). The occurrence probability of $\mathrm{N}$ atoms is marginal since the atomic $\mathrm{N}$ content does not exceed 0.3 at.\%. Literature commonly attributes high activity $\mathrm{N}$-doped carbon electrode materials in ORR to the presence of nitrogen atoms ${ }^{26-29}$. $\mathrm{N}$ atoms are seen as catalytic centers replacing Pt-based catalytic centers as in the commercial reference material denoted as $\mathrm{Pt} / \mathrm{C}$ in this study. Therefore, the observed high electrochemical ORR activity of the G-materials cannot be attributed to the presence of $\mathrm{N}$ atoms and must result from other factors like the improved pore structure and surface area, as proved in the subsequent chapters.

Structure. As mentioned, the manufacturing procedure assumed that graphene planes stacked into bigger blocks were first fragmented to less complex structures (due to the high-pressure liquid phase method), then reorganized, and finally fixed into a 3D porous structure. Thus, single graphene layers (SLG) or few-layered graphene (FLG) were expected to be a building stone of the final structure. Raman spectroscopy studies were performed to investigate this issue. Table 3 and Fig. 3 contain information on the D, G, 2D band placement and intensity. A shift of the $\mathrm{G}$ band towards higher frequencies would have meant a diminishing of the graphene plane agglomeration degree in the thereof materials. However, the differences were not systematic and spectacular, which means that similarly, agglomerated graphene blocks were present in each investigated material, including GF-750. The $\mathrm{I}_{\mathrm{D}} / \mathrm{I}_{\mathrm{G}}$ ratio did not change considerably, too. This means that the size of crystalline domains and the number of defects were comparable for all electrode material samples and GF-750. The intensity ratio $\mathrm{I}_{2 \mathrm{D}} /$ $\mathrm{I}_{\mathrm{G}}$ and $\mathrm{I}_{\mathrm{D}} / \mathrm{I}_{\mathrm{G}}$ of investigated samples indicate that the obtained samples are consisting the multilayer nature of the graphene. The Raman data allowed us to conclude that the liquid phase splitting of GF-750 dispersed graphene packages existing GF-750 in the liquid phase rather than intensively splitting the packages to SLG. The carbonization temperature of the samples affects both the position of the G and 2D bands. G-900 sample had more vacancies and disorders since it has the highest $\mathrm{I}_{\mathrm{D}} / \mathrm{I}_{\mathrm{G}}$ ratio and the highest carbon at. $\%{ }^{30}$. However, the $\mathrm{G}$ band position of G-900 was in a higher wavenumber compare to G-700 or G-800 sample. The observed 2D band intensity decreases with increasing numbers of graphene layers and carbonization range ${ }^{31}$.

The exfoliation to FLG, although not fully confirmed by the Raman studies, was proved by HRTEM structural investigations. Figure 4 documents that FLG structures are definitely present in the electrode materials, in contrast to GF-750, in which they occur rarely. Figure 4 (right) demonstrates the presence of dark "dashes", which are edges of FLG oriented perpendicular to the observation point. A high-resolution image, i.e. Figure 4 (left), confirms this since the "dashes" are built of few parallel stack individual graphene planes. Additionally, it can be concluded that the analyzed materials are pure without a residue of the used template. Thus, the HRTEM and Raman investigations are consistent as for the structure of the investigated samples. In turn, Fig. 5 presents SEM images of obtained materials. All samples had similar irregular and porous surface characteristics, are good quality and again confirm the purity without a residue of the used $\mathrm{CaCO}_{3}$. These images showed a dense $3 \mathrm{D}$ pore 


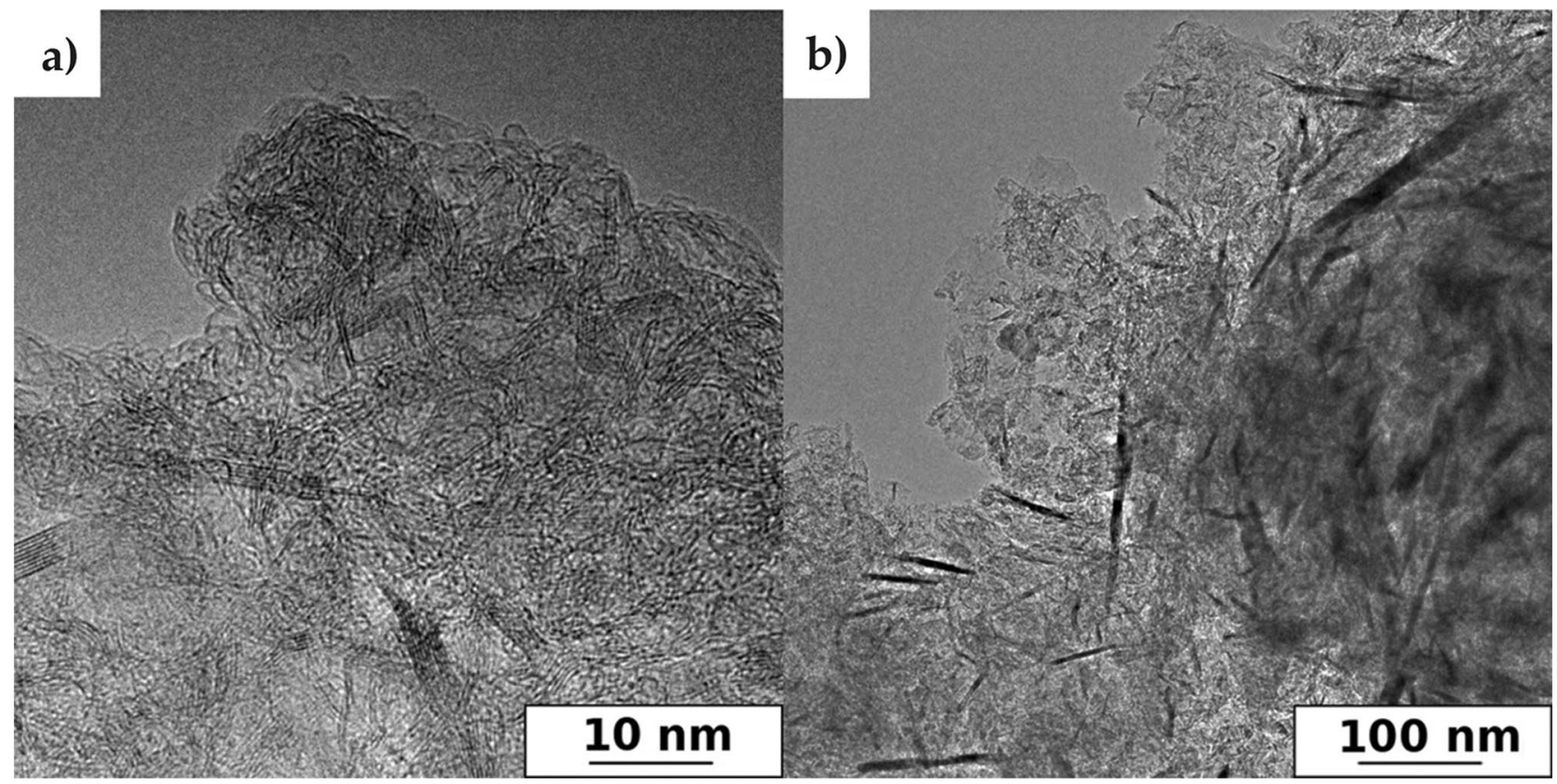

Figure 4. HRTEM images of graphene-based electrode materials. FLG (below 10 layers) packages detected in G-700 (left—high resolution) and G-800 (right-low resolution).

(a)

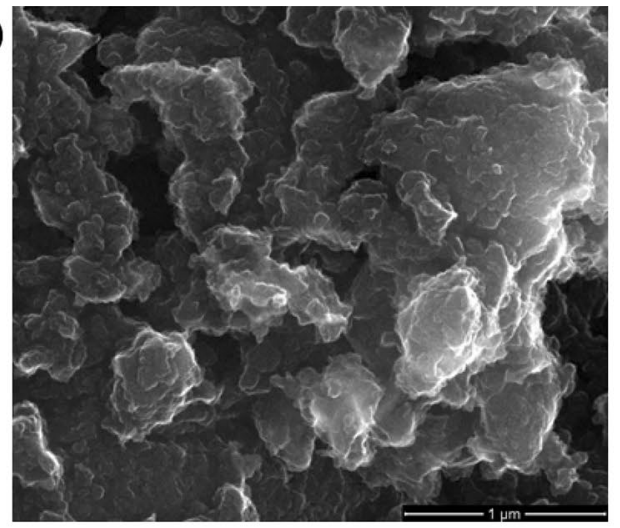

(c)

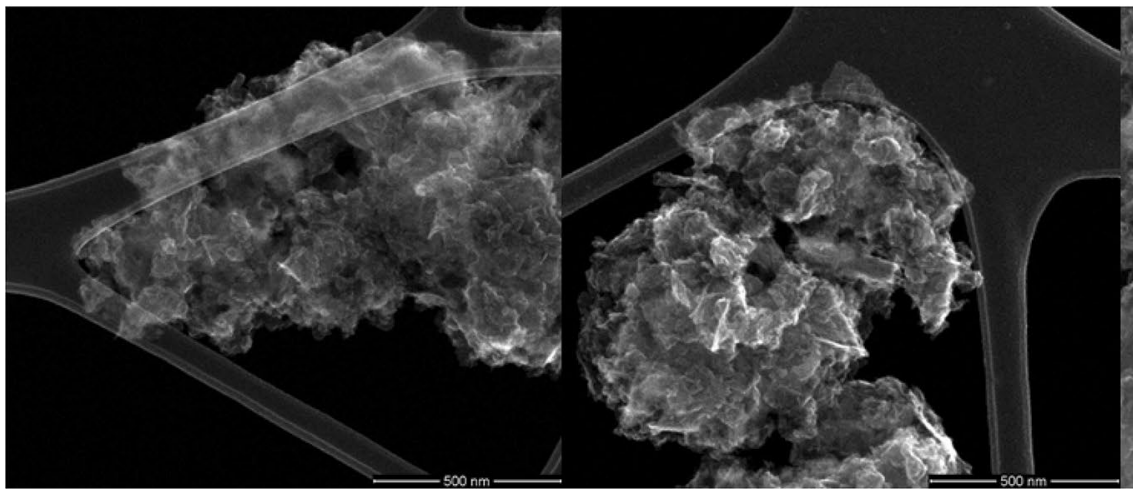

(b)

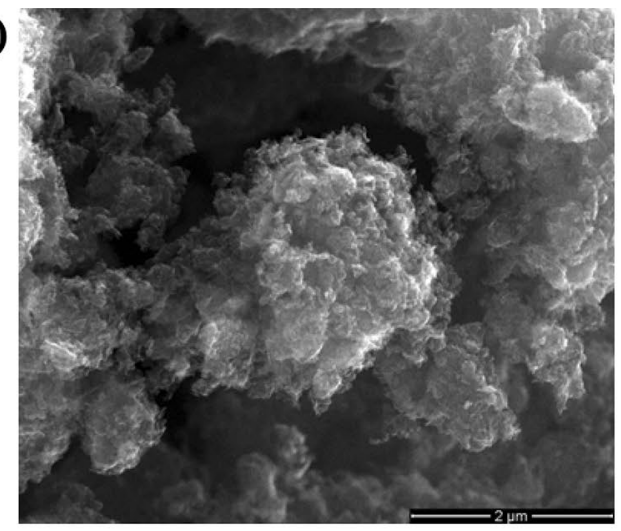

(e)

Figure 5. SEM images of samples (a) GF-750, (b) G-800, and in the STEM mode (c) G-700, (d) G-800 and (e) G-900. 
a)

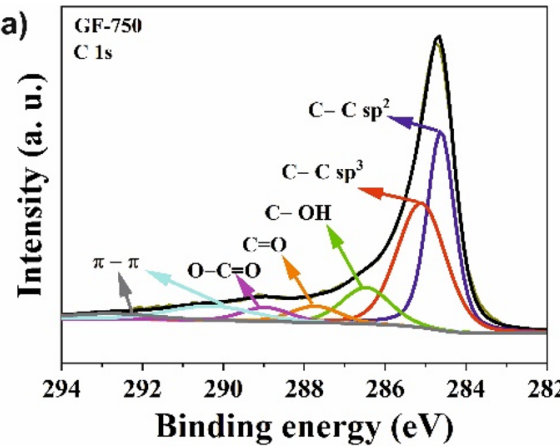

c)

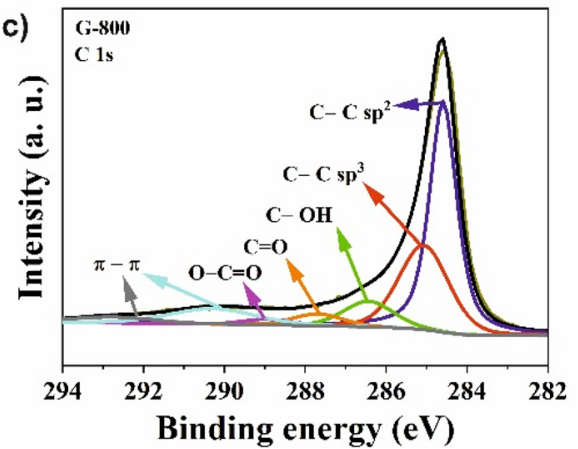

b)

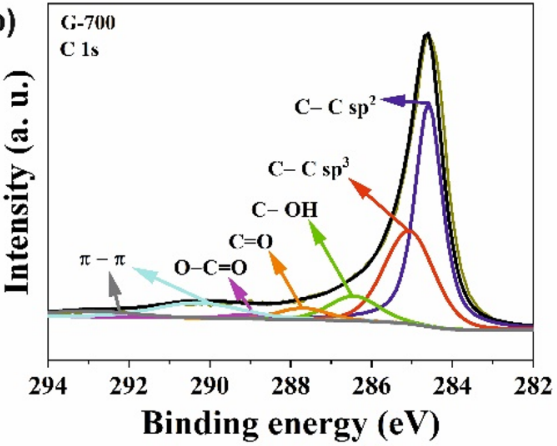

d)

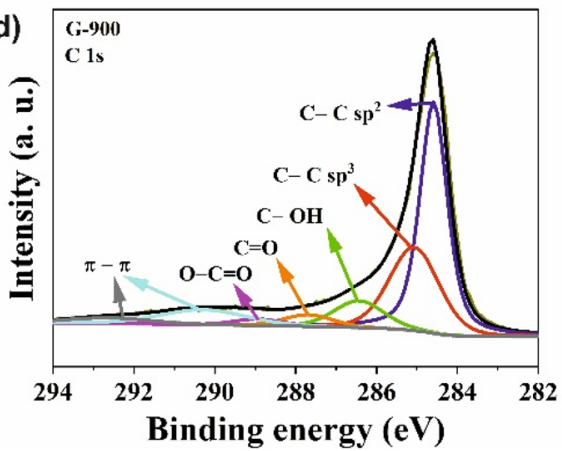

Figure 6. High-resolution X-ray photoelectron spectra for C1s of all investigated samples: (a) C1s of GF-750, (b) C1s of G-700, (c) C1s of G-800, and (d) C1s of G-900.

structure of materials. Generally, the SEM images do not fully allow to determine the degree of graphene sheets deglomeration in these 3D structures.

Surface chemistry. High-resolution XPS studies were performed to determine the chemical structure of the investigated G-materials and pristine GF-750 graphene. Surface elemental composition data are presented in Table 2. The XPS spectra of all investigated samples are demonstrated in Figs. 6 and 7. The analysis of the C1s energy is essential in determining the chemical bonding of carbon atoms. The elemental content of the obtained carbons was high, ranging from 95.9 to 96.7 at.\%. In comparison to raw material, GF-750 is observed increased carbon content of about 2.6-3.4 at.\%. Carbon atoms were mostly bonded as sp $\mathrm{sp}^{2}$ hybridized atoms (band C $1 \mathrm{~s}$ at a binding energy of $284.6 \mathrm{eV}$ ), which is characteristic of graphene materials. The C1s spectra of the obtained materials are composed of seven peaks corresponding to $\mathrm{C}=\mathrm{C}$ bond $\left(\mathrm{sp}^{2}\right)$ peak at $284.6 \mathrm{eV}^{32}, \mathrm{C}-\mathrm{C}$ bonds $\left(\mathrm{sp}^{3}\right)$ peak at $285.0 \mathrm{eV}^{33}, \mathrm{C}-\mathrm{O}-\mathrm{C}$ or $\mathrm{C}-\mathrm{OH}$ bond peak at $286.3 \mathrm{eV}^{34}, \mathrm{C}=\mathrm{O}$ or $\mathrm{O}-\mathrm{C}-\mathrm{O}$ bond peak at $287.7 \mathrm{eV}^{32}$, and peaks with binding energy at $289.6 \mathrm{eV}$ and $292.1 \mathrm{eV}$ are associated with shake-up excitation ${ }^{32}$. The total amount of oxygen in the obtained samples is in the range of 3.3-3.9 at.\%, respectively. In turn, the raw material GF-750 has 6.8 at.\% of oxygen.

Electrochemical performance. The catalytic activity of carbon materials was investigated using the techniques of cyclic voltammetry (CV) and linear sweep voltammetry (LSV). All measurements were made in $0.1 \mathrm{M}$ $\mathrm{KOH}$ saturated with oxygen and nitrogen. The voltammogram in Fig. 8a shows the CV curves from which a clear cathode peak (Ep) is visible in all the obtained graphene materials. The cathode peak is clear for all samples. Table 4 shows the oxygen reduction reaction parameters necessary to characterize the catalytic activity of the electrocatalyst. The value of the cathode peak for commercial platinum-based carbon (Pt/C, $20 \% \mathrm{wt}$.) is $0.76 \mathrm{~V}$ versus RHE, while for the samples, clear peaks are observed for G-700, G-800, G-900 versus RHE, amounting to $0.79 \mathrm{~V}, 0.78 \mathrm{~V}, 0.78 \mathrm{~V}$ and $0.80 \mathrm{~V}$, respectively. Further linear sweep voltammetry (LSV) measurements were performed with a rotating disc electrode (RDE) in the rpm range of 800-2800 in an $\mathrm{O}_{2}$ saturated electrolyte of $0.1 \mathrm{M} \mathrm{KOH}$. Table 4 shows the starting potential values for each sample at $1600 \mathrm{rpm}$ resulting from the linear RDE sweep (Fig. 8b).

Szczesniak et al. ${ }^{35}$ proved that in carbon materials, some intrinsic structures as armchair edges and zigzag edges could strongly interact with neighbouring carbon atoms and change their electronic structure similar to the inserted heteroatoms doping in several different configurations could also significantly alter the electron distribution of dopants and adjacent $\mathrm{C}$ atoms via the delocalization of $\pi$ electrons, thereby affecting the physical and chemical properties. Similarly, constructing a vacancy/defect by removing a C atom may not only destroy the unity of $\pi$ conjugation but also exert a significant influence on the electronic structure of adjacent $\mathrm{C}$ atoms.

Nørskov et al. ${ }^{36}$ defined a possible ORR mechanism involving two key stages: an associative mechanism involving a $\mathrm{HOO}^{\star}$ species and a direct $\mathrm{O}_{2}$ dissociation mechanism in an acid or alkaline electrolyte. In an alkaline environment, the following steps may occur: 

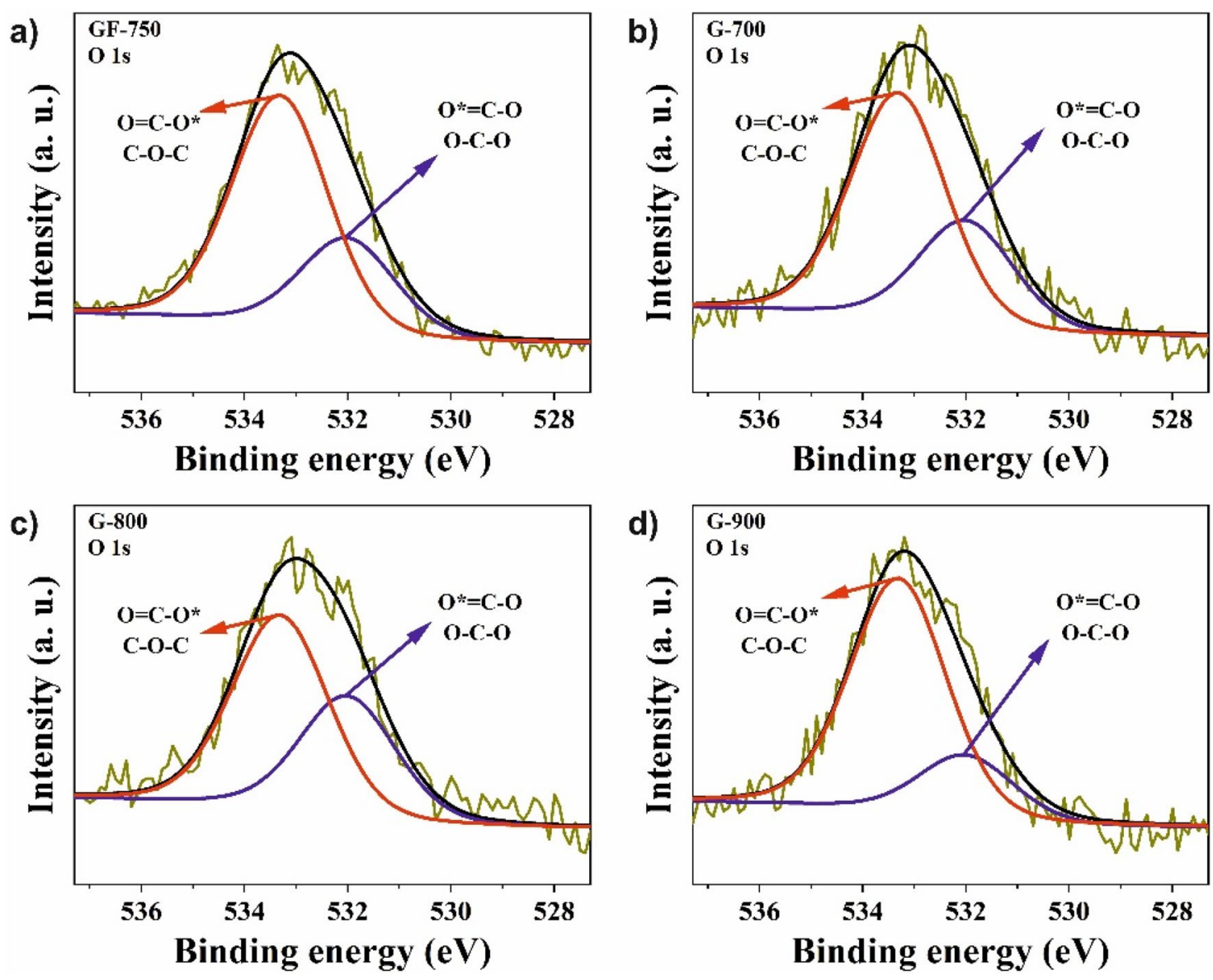

Figure 7. High-resolution X-ray photoelectron spectra for O1s of all investigated samples: (a) O1s of GF-750, (b) O1s of G-700, (c) O1s of G-800, and (d) O1s of G-900.

$$
\begin{gathered}
\mathrm{O}_{2(\mathrm{~g})}+* \rightarrow \mathrm{O}_{2}^{*} \\
\mathrm{O}_{2}^{*}+\mathrm{H}_{2} \mathrm{O}(\mathrm{I})+e^{-} \rightarrow \mathrm{HOO}^{*}+\mathrm{OH}^{-} \\
\mathrm{HOO}^{*}+e^{-} \rightarrow \mathrm{O}^{*}+\mathrm{OH}^{-} \\
\mathrm{O}^{*}+\mathrm{H}_{2} \mathrm{O}(\mathrm{I})+e^{-} \rightarrow \mathrm{HO}^{*}+\mathrm{OH}^{-} \\
\mathrm{HO}^{*}+e^{-} \rightarrow \mathrm{OH}^{-}+*
\end{gathered}
$$

The mechanism via direct $\mathrm{O}_{2}$ dissociation of oxygen atoms starts with the following elementary step:

$$
\mathrm{O}_{2(g)}+*+* \rightarrow \mathrm{O}^{*}+\mathrm{O}^{*}
$$

followed by steps (6) and (7) in alkaline solution.

Where ${ }^{\star}$ stands for an active site on the surface of electrocatalyst, $(I)$ and (g) refer to liquid and gas phases, respectively, and $\mathrm{O}^{\star}, \mathrm{OH}^{\star}$ and $\mathrm{HOO}^{\star}$ are the adsorbed intermediates.

Splitting of graphene flakes contributes to the enlargement of specific surface areas and opens active sites such as carbon atom vacancies, which are less accessible in the case of stacked graphene sheets. We assume it is the main reasoning for the observed increase of ORR activity. The number of transferred electrons in ORR, i.e. $\mathrm{n}$, is the highest for G-800 and G-900, also having the most advanced structural parameters as surface area and the total pore volume.

The ORR highest-performing material of the investigated graphene-based electrodes is G-900, which catalyzes the ORR at potentials within $160 \mathrm{mV}$ of the paternal $\mathrm{Pt} / \mathrm{C}$ electrode for a current of $1 \times 10^{-2} \mathrm{~mA} \mathrm{~cm}^{-2}$. However, the differences between G-900 and G-800/G-700 are visible but not spectacular. This is in contrast to the pristine GF-750 sample, which performs ORR much worse. Using the Koutecky-Levich diagram (Fig. 8c), it is possible to determine the number of transferred electrons in the oxygen reduction reaction at the value of $0.5 \mathrm{~V}$. The results for each catalyst obtained in the speed range $(800-2800 \mathrm{rpm})$ showed a linear character, which indicates the correct spread of electron transfer in the ORR reaction. The number of transferred electrons (Table 4 
(a)

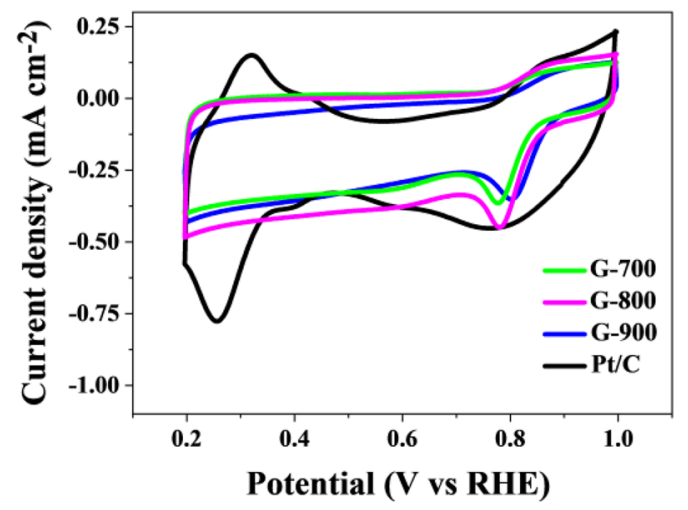

(c)

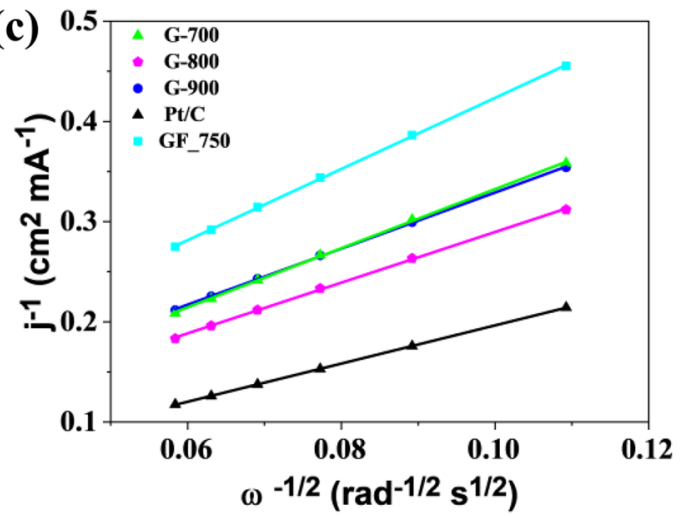

(b)

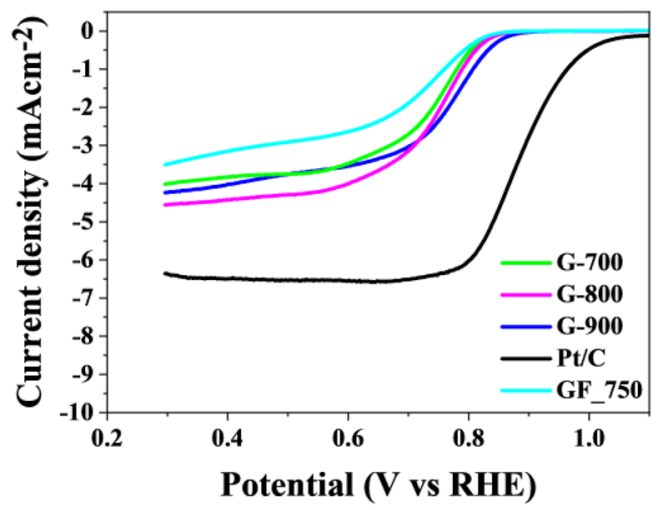

(d)

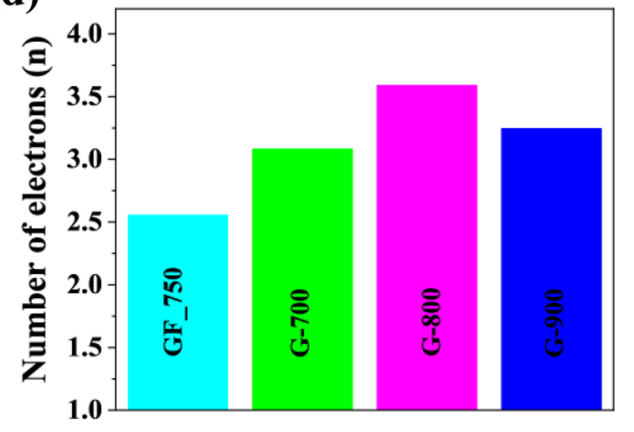

Figure 8. (a) $\mathrm{CV}$ curves of the obtained electrocatalysts and $\mathrm{Pt} / \mathrm{C}$ catalysts in an $\mathrm{O}_{2}$-saturated $0.1 \mathrm{M} \mathrm{KOH}$ solution; (b) LSV curves of G-700, G-800, G-900 and Pt/C catalysts measured at a scan rate of $5 \mathrm{mV} \mathrm{s}^{-1}$ and a rotation rate of $1600 \mathrm{rpm}$ in $\mathrm{O}_{2}$-saturated $0.1 \mathrm{M} \mathrm{KOH}$ solution; (c) Koutecky-Levich plots in the potential $0.5 \mathrm{~V}$; (d) the number of transfer electrons in the oxygen reduction reaction.

\begin{tabular}{|l|l|l|l|l|l|}
\hline Catalysts & $\mathbf{E}_{\mathbf{p}}(\mathbf{V}$ vs. RHE) & $\mathbf{E}_{\text {onset }}(\mathbf{V}$ vs. RHE) & $\mathbf{E}_{1 / 2}$ (V vs. RHE) & Diffusion-limiting current $\left(\mathbf{m A ~ c m}^{-2}\right)$ & $\mathbf{n}(\mathbf{0 . 5} \mathbf{~ V})$ \\
\hline Pt/C $(20 \%$ wt. $)$ & 0.76 & 1.03 & 0.88 & 6.37 & 4.00 \\
\hline GF-750 & 0.77 & 0.821 & 0.73 & 2.78 & 2.56 \\
\hline G-700 & 0.78 & 0.818 & 0.75 & 3.73 & 3.08 \\
\hline G-800 & 0.78 & 0.823 & 0.75 & 4.25 & 3.59 \\
\hline G-900 & 0.80 & 0.846 & 0.78 & 3.46 & 3.25 \\
\hline
\end{tabular}

Table 4. ORR performance parameters of the obtained reactor carbon and commercial $\mathrm{Pt} / \mathrm{C}$ catalysts tested in alkaline media.

and Fig. 8d) for most of the obtained carbon materials is above 3. The highest value of the number of electrons transferred for the G-800 sample is 3.6, which indicates a similar 4-electron oxygen reduction reaction as in the case of a commercial catalyst. The obtained materials, despite the low nitrogen content in the structure, show increased catalytic activity. As demonstrated in our previous work ${ }^{37}$ electrode material properties are predominantly affected by their pore structure, carbonization temperature, modification of structure and the presence of heteroatoms. Not all of these critical parameters have a positive effect on the electrochemical performance of the carbons in ORR. The high surface area and porosity of the obtained graphene materials allow for unforced access of the $\mathrm{KOH}$ electrolyte into the porous structure, increasing the catalytic activity. Therefore, these materials can be successfully used as metal-free catalysts in devices based on the oxygen reduction reaction, such as metal-air batteries or fuel cells. The porosity of the graphene structure has a significant impact on the catalytic activity, and the appropriate pore size means that materials with a high surface area can also be used in energy storage devices. For the sample with the highest surface area, the applicability of the obtained materials was tested as a $\mathrm{Zn}$-air battery.

The improvement of the ORR performance of G-materials against pristine GF-750 is spectacular, i.e. the key parameter " $n$ " increased from 2.56 to 3.59 in the case of G-800. It has to be noted that the efficient ORR performance was achieved due to 3D structuring (improvement of surface area and pore structure), while the chemical purity was much better for G-materials. Therefore, the high ORR activity of G-materials should not be ascribed to heteroatom catalytic centers since such heteroatoms were successively removed upon increasing the carbonization temperature. The XPS data showed that the presence of transition metals (usually regarded 

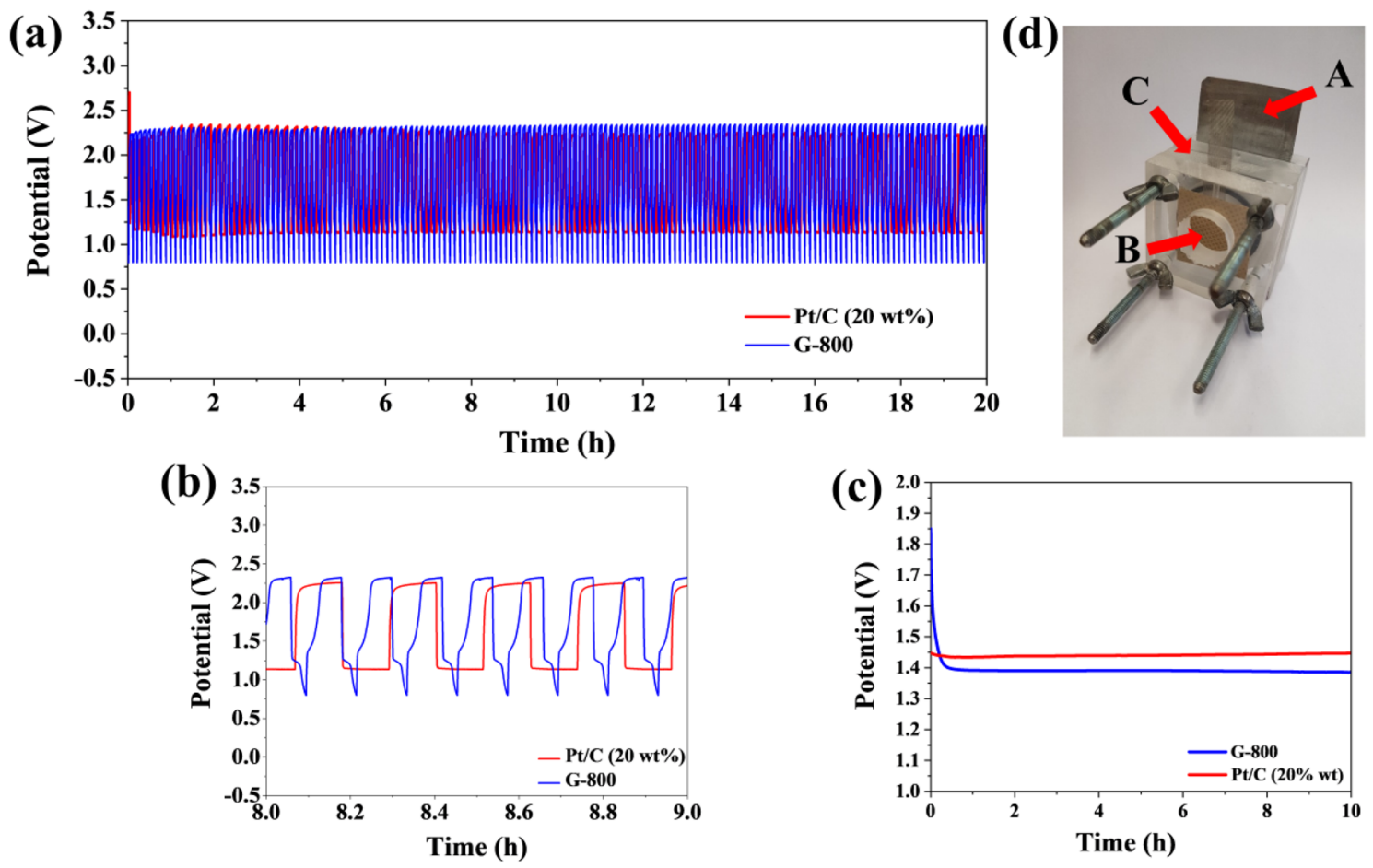

Figure 9. (a) Galvanostatic charge/discharge cycling curves at $1 \mathrm{~mA} \mathrm{~cm}{ }^{-2}$ of $\mathrm{Zn}$-air batteries incorporating the G-800 catalyst and the commercial Pt/C catalyst, respectively; (b) galvanostatic charge/discharge cycling in the selected range; (c) galvanostatic discharge curves at $1 \mathrm{~mA} \mathrm{~cm}{ }^{-2}$ for G-800 catalysts and the commercial Pt/C catalyst; (d) photograph of the handmade rechargeable $\mathrm{Zn}$-air battery with an open-circuit voltage of $1.38 \mathrm{~V}$, where (A) Zn electrode, (B) air electrode (GDL made of the catalyst under investigation), (C) electrolyte $6 \mathrm{M}$ $\mathrm{KOH}$ with $0.2 \mathrm{M} \mathrm{ZnCl}_{2}$.

as catalytic centers) in G-materials was marginal. Also, the content of nitrogen atoms potentially being active in ORR was neglectable. The results point out the importance of the structural factors of electrodes in the case of graphene-based materials and ORR.

Based on the results of the oxygen reduction reaction, the material with the highest transferred electron number was selected and used as an oxygen catalyst in the construction of the metal-air battery. The purpose of this study was to check the applicability of the obtained graphene materials. Zn-air batteries were self-designed and handmade (Fig. 9d). For this purpose, a zinc plate was used as an anode electrode, separator and the abovementioned carbon paper with a charged catalyst with a packing of $1 \mathrm{mg} / \mathrm{cm}^{2}$. The charge/discharge tests for the best catalyst were compared to a metal-air battery made of a platinum-based carbon catalyst (Pt/C $20 \mathrm{wt}$.\%). Three hundred charging/discharging cycles were performed (one cycle consisted of 300 charges and 300 discharges). The stability of the open circuit potential (OCP) confirms the effective operation of $\mathrm{Zn}$-air batteries $1.38 \mathrm{~V}$. Compared to the $\mathrm{Pt} / \mathrm{C}$ catalyst, whose potential was $1.45 \mathrm{~V}$, the potential for the catalyst obtained with our method was close to this value. It can be assumed that the excellent charge/discharge stability, shown in Fig. 9, was the presence of a high surface area, a mesoporous structure responsible for the catalytic activity. The charge/discharge tests were conducted at a current density of $1 \mathrm{~mA} / \mathrm{cm}^{2}$. They showed stability in the range of $2.27 \mathrm{~V}$ for a charged battery and $0.9 \mathrm{~V}$ for the discharged process. The potential range for $\mathrm{Zn}$-air batteries with a G-800 catalyst is stable over a long period of time. After $6 \mathrm{~h}$ of charge/discharge cycles, the potential of the battery with the commercial catalyst falls, while the battery with the metal-free catalyst keeps its charging stability throughout the charging/discharging process. The obtained mesoporous graphene material can be successfully used as electrode material in devices using the oxygen reduction reaction, and due to the appropriate specific surface area and pore size, the use of this material can be extended for application in supercapacitors.

\section{Conclusions}

In summary, we have demonstrated a low-cost method to obtaining high surface area mesoporous graphene materials. We have shown that the porous structure of the material is of key importance in electrochemical applications. The obtained mesoporous graphene material can be successfully used as electrode material in devices using the Oxygen Reduction Reaction, and due to the appropriate specific surface area and pore size, the use of this material can be extended for application in supercapacitors. These aspects of the performed study will be continued in further research.

Received: 25 August 2021; Accepted: 11 October 2021

Published online: 11 November 2021 


\section{References}

1. Ravindran, A. R. et al. Effects of graphene nanoplatelet size and surface area on the AC electrical conductivity and dielectric constant of epoxy nanocomposites. Polymers 10, 477 (2018).

2. Um, J. G. et al. Investigation of the size effect of graphene nano-platelets (GnPs) on the anti-corrosion performance of polyurethane/ GnP composites. RSC Adv. 8, 17091-17100 (2018).

3. Graphenea, T. P. O. G. The Price of Graphene-Graphenea.

4. Coleman, J. N. Liquid exfoliation of defect-free graphene. Acc. Chem. Res. 46, 14-22 (2013).

5. Cai, M., Thorpe, D., Adamson, D. H. \& Schniepp, H. C. Methods of graphite exfoliation. J. Mater. Chem. 22, 24992-25002 (2012).

6. Coleman, J. N. Liquid-phase exfoliation of nanotubes and graphene. Adv. Funct. Mater. 19, 3680-3695 (2009).

7. Yuan, L. et al. A reliable way of mechanical exfoliation of large scale two dimensional materials with high quality. AIP Adv. 6, 125201 (2016).

8. Cui, X., Zhang, C., Hao, R. \& Hou, Y. Liquid-phase exfoliation, functionalization and applications of graphene. Nanoscale 3, 2118-2126 (2011).

9. Zhong, Y. L., Tian, Z., Simon, G. P. \& Li, D. Scalable production of graphene via wet chemistry: Progress and challenges. Mater. Today 18, 73-78 (2015).

10. Park, S. \& Ruoff, R. S. Chemical methods for the production of graphenes. Nat. Nanotechnol. 4, 217-224 (2009).

11. Xin, G., Hwang, W., Kim, N., Cho, S. M. \& Chae, H. A graphene sheet exfoliated with microwave irradiation and interlinked by carbon nanotubes for high-performance transparent flexible electrodes. Nanotechnology 21, 405201 (2010).

12. Yi, M. \& Shen, Z. A review on mechanical exfoliation for the scalable production of graphene. J. Mater. Chem. A 3, 11700-11715 (2015).

13. Raccichini, R., Varzi, A., Passerini, S. \& Scrosati, B. The role of graphene for electrochemical energy storage. Nat. Mater. 14, 271-279 (2015).

14. Ilnicka, A., Skorupska, M., Romanowski, P., Kamedulski, P. \& Lukaszewicz, J. P. Improving the performance of Zn-air batteries with N-doped electroexfoliated graphene. Materials 13, 2115 (2020).

15. Ilnicka, A., Skorupska, M., Kamedulski, P. \& Lukaszewicz, J. P. Electro-exfoliation of graphite to graphene in an aqueous solution of inorganic salt and the stabilization of its sponge structure with poly (furfuryl alcohol). Nanomaterials 9,971 (2019).

16. Ilnicka, A. \& Lukaszewicz, J. P. Nanoscale exfoliation of graphene sheets for manufacturing of 3D mesoporous structures. J. Nanosci. Nanotechnol. 16, 9997-10000 (2016).

17. Kamedulski, P., Ilnicka, A., Lukaszewicz, J. P. \& Skorupska, M. Highly effective three-dimensional functionalization of graphite to graphene by wet chemical exfoliation methods. Adsorption 25, 631-638 (2019).

18. Ilnicka, A., Kamedulski, P., Skorupska, M. \& Lukaszewicz, J. P. Metal-free nitrogen-rich carbon foam derived from amino acids for the oxygen reduction reaction. J. Mater. Sci. 54, 14859-14871 (2019).

19. Wang, S. et al. Activation routes for high surface area graphene monoliths from graphene oxide colloids. Carbon 76, 220-231 (2014).

20. Wang, S. et al. Correlation in structure and properties of highly-porous graphene monoliths studied with a thermal treatment method. Carbon 96, 174-183 (2016).

21. Wang, S., Yoshikawa, Y., Wang, Z., Tanaka, H. \& Kaneko, K. Highly oxidation-resistant graphene-based porous carbon as a metal catalyst support. Carbon Trends 3, 100029 (2021).

22. Wang, S. \& Kaneko, K. Highly nanoporous graphene monoliths. Acc. Mater. Surf. Res. 3, 100-119 (2018).

23. Xia, K. et al. Controllable fabrication of 2D and 3D porous graphene architectures using identical thermally exfoliated graphene oxides as precursors and their application as supercapacitor electrodes. Microporous Mesoporous Mater. 237, 228-236 (2017).

24. Zhang, L. et al. Porous 3D graphene-based bulk materials with exceptional high surface area and excellent conductivity for supercapacitors. Sci. Rep. 3, 1-9 (2013).

25. Sotomayor, F. J., Cychosz, K. A. \& Thommes, M. Characterization of micro/mesoporous materials by physisorption: Concepts and case studies. Acc. Mater. Surf. Res. 3, 34-50 (2018).

26. Naumov, O., Naumov, S., Abel, B. \& Varga, A. The stability limits of highly active nitrogen doped carbon ORR nano-catalysts: A mechanistic study of degradation reactions. Nanoscale 10, 6724-6733 (2018).

27. Ma, R. et al. A review of oxygen reduction mechanisms for metal-free carbon-based electrocatalysts. NPJ Comput. Mater. 5, 1-15 (2019).

28. Lv, Q. et al. Selectively nitrogen-doped carbon materials as superior metal-free catalysts for oxygen reduction. Nat. Commun. 9, $1-11$ (2018).

29. Guo, C. et al. A highly nanoporous nitrogen-doped carbon microfiber derived from bioresource as a new kind of ORR electrocatalyst. Nanoscale Res. Lett. 14, 1-11 (2019).

30. Ferrari, A. C. \& Robertson, J. Interpretation of Raman spectra of disordered and amorphous carbon. Phys. Rev. B 61, 14095 (2000).

31. Park, J. et al. G' band Raman spectra of single, double and triple layer graphene. Carbon 47, 1303-1310 (2009).

32. Arendt, M. F., Beamson, G. \& Briggs, D. High resolution XPS of organic polymers: The scienta ESCA300 database. J. Am. Chem. Soc. 115, 12229-12229 (1993).

33. Rouxhet, P. G. \& Genet, M. J. XPS analysis of bio-organic systems. Surf. Interface Anal. 43, 1453-1470 (2011).

34. Yumitori, S. Correlation of C1s chemical state intensities with the O1s intensity in the XPS analysis of anodically oxidized glass-like carbon samples. J. Mater. Sci. 35, 139-146 (2000).

35. Szczesniak, D., Durajski, A. P., Khater, A. \& Ghader, D. Energy band gaps in graphene nanoribbons with corners. Europhys. Lett. 114, 48001 (2016).

36. Nørskov, J. K. et al. Origin of the overpotential for oxygen reduction at a fuel-cell cathode. J. Phys. Chem. B 108, 17886-17892 (2004).

37. Kamedulski, P., Lukaszewicz, J. P., Witczak, L., Szroeder, P. \& Ziolkowski, P. The importance of structural factors for the electrochemical performance of graphene/carbon nanotube/melamine powders towards the catalytic activity of oxygen reduction reaction. Materials 14, 2448 (2021).

\section{Acknowledgements}

All experimental work (synthesis, analysis) was supported by the National Science Centre (Poland) Grant 2016/23/B/ST5/00658.

\section{Author contributions}

P.K.: Conceptualization, methodology, investigation, formal analysis, visualization, writing-original draft, writing - review and editing, supervision. M.S.: Investigation, Formal analysis, visualization, writing-original draft, writing - review and editing. P.B.: Visualization, investigation. W.A.: Investigation. A.I.: Technical help. J.P.L.: Conceptualization, formal analysis, writing-original draft, writing-review and editing, supervision, project administration, funding acquisition. All authors have read and agreed to the published version of the manuscript. 


\section{Competing interests}

The authors declare no competing interests.

\section{Additional information}

Correspondence and requests for materials should be addressed to J.P.L.

Reprints and permissions information is available at www.nature.com/reprints.

Publisher's note Springer Nature remains neutral with regard to jurisdictional claims in published maps and institutional affiliations.

(c) (1) Open Access This article is licensed under a Creative Commons Attribution 4.0 International License, which permits use, sharing, adaptation, distribution and reproduction in any medium or format, as long as you give appropriate credit to the original author(s) and the source, provide a link to the Creative Commons licence, and indicate if changes were made. The images or other third party material in this article are included in the article's Creative Commons licence, unless indicated otherwise in a credit line to the material. If material is not included in the article's Creative Commons licence and your intended use is not permitted by statutory regulation or exceeds the permitted use, you will need to obtain permission directly from the copyright holder. To view a copy of this licence, visit http://creativecommons.org/licenses/by/4.0/.

(C) The Author(s) 2021 